\title{
Appreciation of the delay in the benefits of the thermal energy released by PCM in civil engineering structures
}

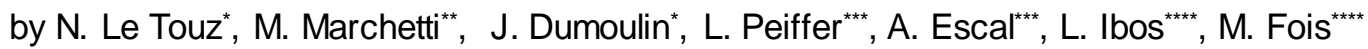 \\ and P. Bourson
}

\author{
*IFSTTAR, COSYS-SII \& Inria, I4S Team, Allée des Ponts et Chaussée, F-44340, Bouguenais, France, \\ nicolas.le-touz@ifsttar.fr \\ ${ }^{* \star}$ Cerema - Est \& Université de Lorraine - CentraleSupelec, LMOPS, 71 rue de la Grande haie, 54510 \\ Tomblaine, France, mario.marchetti@cerema.fr \\ ${ }^{* \star *}$ Cerema - Est, 71 rue de la Grande haie, 54510 Tomblaine, France

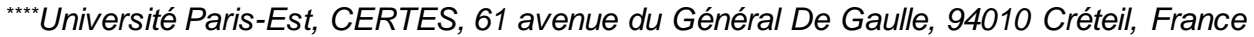 \\ ${ }^{\star \star * \star \star}$ Université de Lorraine - CentraleSupelec, LMOPS, 2 avenue Edouard Belin, 57070 Metz, France
}

\begin{abstract}
To optimize de-icers use in winter on roads and airports, some sustainable solutions were promoted in a global project entitled "Roads of the Future". PCM into pavements were then considered to rely on the released enthalpy to delay the occurrence of black ice or snow accumulation. Coupling a spectroscopic monitoring of the PCM behavior and thermography on pavement surface indicated a significant delay between the phase change and the thermal manifestation of the released energy. Considering an accurate description of PCM according to cooling weather phenomena, these elements might provide valuable information for numerical models.
\end{abstract}

\section{Introduction}

Maintaining mobility on roads and the possibility for aircrafts to land and to take-off is a major issue in poor weather conditions as encountered in winter. Many efforts have been developed over the years to evaluate the economical costs of winter maintenance [1], its environmental impacts [2] or to forecast these adverse situations [3-6]. Still the amounts of de-icers are increasing, conducting to consider a modification of the infrastructure itself to make it compliant with the avoidance of ice occurrence and snow accumulation, as performed on the Serso bridge in Switzerland [7]. Previous research indicated the benefits of a multilayered asphalt concrete [8] and phase change materials (PCM) included into a pavement [9]. These inclusions are meant to maintain a constant surface temperature during the phase transition process. The phase transition did indeed take place but often not at the temperature provided by the PCM manufacturer. Furthermore, a delay is expected between the moment the phase transition occur and its thermal detection at the surface. Coupling a spectroscopic monitoring of the PCM behavior and a thermographic one of the pavement surface allowed to quantifying subcooling effect and this delay in the benefits of the energy released during the phase change. These elements could therefore be implemented in numerical models to properly appreciate to what extent these PCM could contribute to a sustainable winter maintenance.

\section{Coupling infrared thermography and Raman spectroscopy to pavement monitoring}

The main idea was to identify to what extent the energy released during the solid to liquid phase transition of a PCM embedded into a pavement was able to increase the pavement surface temperature. But because of the PCM volume and the poor and heterogeneous thermal characteristics, the determination of the time necessary for this available released energy to reach the surface was difficult to appreciate. This time was difficult to identify for two reasons. First, the PCM being embedded into a non transparent material, the phase change can not be observed. The second aspect is related to subcooling phenomena that can hardly be predicted since they depend on the experimental conditions. So as to identify the moment the phase transition is taking place, a Raman probe was inserted within the PCM container, the spectral signature being different according to the phase of the material.

\subsection{Pavement, PCM samples and test facility}

Two pavement samples were manufactured, and were parallelepipeds of $10 \mathrm{~cm} \times 18 \mathrm{~cm} \times 50 \mathrm{~cm}$, of semi-granular asphalt concrete (granular materials with a bitumen matrix). This material is very common either on national roads, highways and taxiways. The first one was a pristine asphalt concrete one used as reference. Some wood inclusions of different heights were placed into the second sample during the manufacturing to generate voids where PCM inclusions in appropriate metallic containers were placed (figure 1a). One of the inclusions is then located $3.9 \mathrm{~cm}$ below the surface and the second one $2.8 \mathrm{~cm}$. All pavement samples sides were surrounded by extruded polystyrene to provide a thermal insulation of the samples and to avoid lateral losses. 


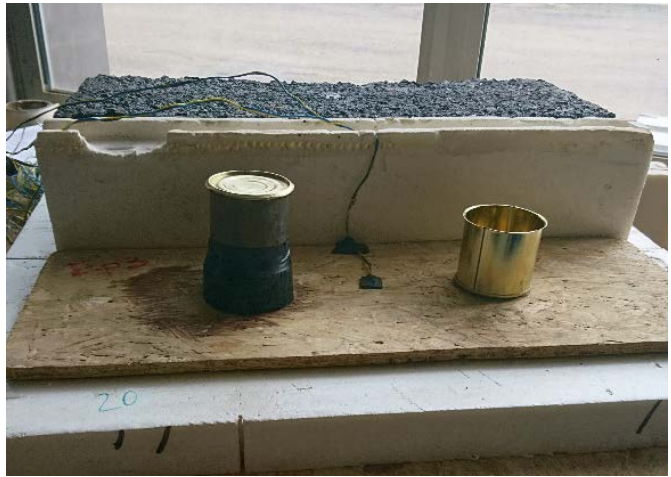

(a)

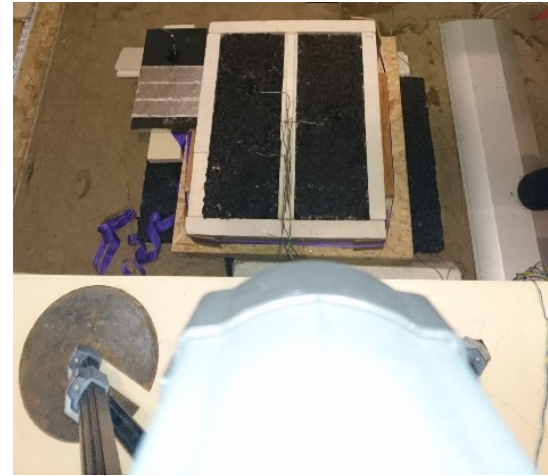

(b)

Fig. 1. Pristine pavement sample and PCM metallic containers before installation of pavement sample with voids with T-type thermocouples (a) and pavements samples with FLIR A320G infrared camera (b)

Both pavement samples were then placed on the floor of a climatic chamber before being submitted to a dry air temperature variations $\left(-10^{\circ} \mathrm{C} \leq \mathrm{T}_{\mathrm{air}} \leq+10^{\circ} \mathrm{C}\right)$ representative of a winter in France. The test lasted five days, excluding a preliminary thermal conditioning at $10^{\circ} \mathrm{C}$ for 24 hours. Several thermocouples were attached to both pavement samples and PCM containers to monitor temperature variations during the test.

The selection of PCM relied on some requirements. The first one was to have a liquid to solid phase transition temperature compliant with the winter maintenance context on civil engineering infrastructures. A maximum of $5^{\circ} \mathrm{C}$ was then selected. The second aspect to be considered are the chemical characteristics of the materials, i.e. the potential corrosivity with respect to metals, or their flash points. Therefore, a first PCM inclusion consisted in an aqueous saline solution and with a freezing point of $-5^{\circ} \mathrm{C}$. The second one was a Rubitherm ${ }^{\circledR} \mathrm{SP} 5$, an inorganic material with a freezing temperature in the $2-7^{\circ} \mathrm{C}$ range according to its datasheet.

\subsection{Thermographic and spectroscopic monitoring}

Infrared images were generated with a FLIR A325 (320 x 240 IRFPA, LWIR, pitch $25 \mu \mathrm{m})$, with a NEDT of $0.1^{\circ} \mathrm{C}$. The camera was placed in the climatic chamber with an incidence of roughly $20^{\circ}$ with respect to the pavement samples surfaces, at a distance of $1.5 \mathrm{~m}$ (figure $1 \mathrm{~b}$ ).

The spectroscopic monitoring of the aqueous saline solution as PCM inclusion was obtained with an i-Raman from BWTek ${ }^{\circledR}$ operating with a $532 \mathrm{~nm}$ laser light, and with a spectral resolution of $2 \mathrm{~cm}^{-1}$. An immersion probe was sealed into the container with the PCM, the signal being collected through an optical fibre, the passage being under the pavement samples. One of the great advantage of such experimental configuration is the total absence of external light. Within these conditions, the Raman spectral signature of the PCM was not containing any fluorescence artefacts.

Both instruments were synchronized, with an infrared and Raman spectrum collection every 3 minutes. The over 2000 infrared images were analysed with ThermaCam Researcher ${ }^{\circledR}$ and its associated OLE Automation implemented to extract surface temperature of some transects over pavement samples. Both transects and over 2000 Raman spectra were then analysed by means of principal component analysis (PCA) with Unscrambler ${ }^{\circledR} \times 10.1$ software, using a NIPALS algorithm, as detailed in the literature [9] to identify the PCM phase transition. The same tool was applied to thermal images considering the surface temperature increase will generate an anomaly that a PCA analysis will identify.

\section{Finite elements and numerical simulations}

We propose in this section to perform numerical simulations to compare results issued from measurements with numerical ones. A finite element model was developed to compute the temperature field in the structure from the knowledge of air temperature evolution at boundary. Two pavements samples were studied: a pavement with two inclusions, Rubitherm ${ }^{\circledR}$ SP5 and brine solution, shown in figure 2, and a healthy pavement without inclusion and with the same dimensions than experimental pavement samples.

Thermal diffusion in the structure is governed by the heat equation (1):

$$
\rho c \frac{\partial T}{\partial t}-\nabla \cdot(k \nabla T)=0
$$

Where $\rho$ is the density, $c$ the massic heat capacity and $k$ the thermal conductivity.

We suppose that thermal exchanges of the structure with the outside occur at the surface. Other boundaries are supposed to be adiabatic. Boundary conditions are as follows:

$$
k \nabla T \cdot \vec{n}=h\left(T_{\infty}-T\right)
$$


With $h$ an exchange coefficient and $T_{\infty}$ the temperature far from the structure. Exchanges between the studied domain and the environment take into account convective exchanges with the air and radiative exchanges. Radiative exchanges are supposed to be linearized and environment temperature equal to the measured air temperature.

Applying the finite element method to equations (1) and (2) allows to get a linear system [10]. For the time dependence, we used a Crank-Nicolson scheme.

Three-dimensional view

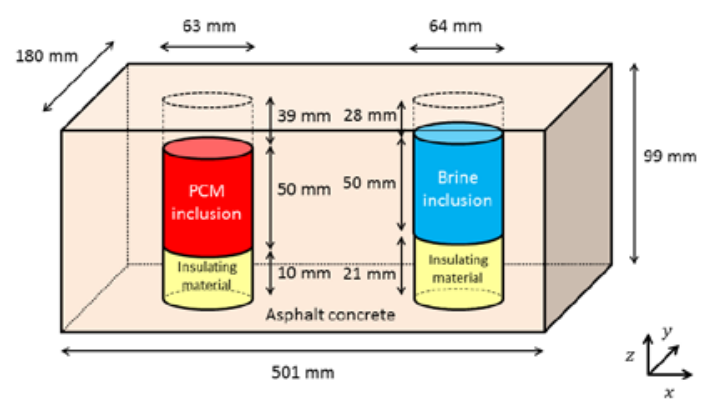

Sectional view in $(x, y)$ plane
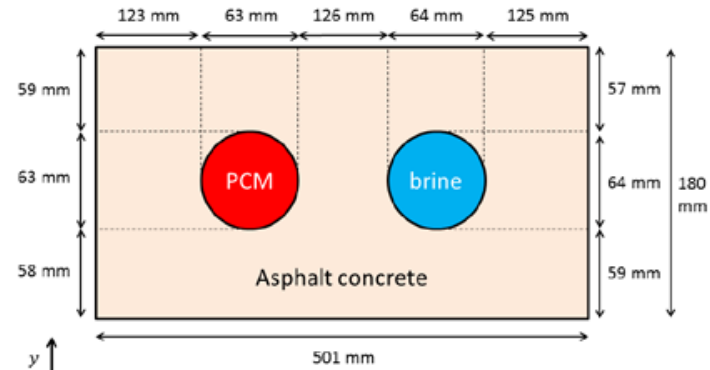

Fig. 2. Schematic view of the domain

We suppose that thermal properties of the asphalt concrete and insulating material are constant. From [11], we use $\rho=2450 \mathrm{~kg} \cdot \mathrm{m}^{-3}, c=920 \mathrm{~J} \cdot \mathrm{kg}^{-1} \cdot \mathrm{K}^{-1}$ and $k=1.40 \mathrm{~W} \cdot \mathrm{m}^{-1} \cdot \mathrm{K}^{-1}$ for asphalt concrete and from [12] $\rho=55 \mathrm{~kg} \cdot \mathrm{m}^{-3}, c=1210$ $\mathrm{J} \cdot \mathrm{kg}^{-1} \cdot \mathrm{K}^{-1}$ and $k=0.027 \mathrm{~W} \cdot \mathrm{m}^{-1} \cdot \mathrm{K}^{-1}$ for insulating material (extruded polystyrene).

Because of the phase change of both brine and SP5, thermal properties of the other materials cannot be considered as constant over the studied temperature range, and particularly along the temperature range of phase change.

Thermal data for SP5 are provided by the supplier [13] and are shown in figure 3. Thermal conductivity is moreover supposed to vary linearly with the temperature.

For the brine solution, we consider a two-phase mixture. The salt quantity is equal to $C_{i, 0}=0.080 \mathrm{~kg}$ per $\mathrm{kg}$ of water, below the saturation value. For a decreasing temperature from a positive temperature, the mixture is first liquid, then, the eutectic temperature is reached and ice begin to form. Salt concentration in the remaining brine solution also increases. Ice formation continues until the eutectic point, at $-20.6^{\circ} \mathrm{C}$ where the $\mathrm{NaCl}$ solution reaches the saturation. If temperature continues to decrease, mixture is composed of ice and solid sodium chloride dihydrate $\left(\mathrm{NaCl}^{-2} \mathrm{H}_{2} \mathrm{O}\right)$. $\mathrm{Phase}$ change occurs also between the eutectic point at $-20.6^{\circ} \mathrm{C}$ and eutectic temperature. We consider here a concentration in $\mathrm{NaCl}$ equal to $80 \mathrm{~g}$ per $\mathrm{kg}$ of water. From values given by [14], the eutectic temperature $T_{l}$ (in ${ }^{\circ} \mathrm{C}$ ) can be interpolated as a function of $\mathrm{NaCl}$ concentration $C$ (in $\mathrm{kg}$ per $\mathrm{kg}$ of water):

$$
T_{l}(C)=-55.3 C-42.05 C^{2}
$$

Thermal capacity can be computed from infinitesimal variations of enthalpy $d H$ that come from variations of temperature for ice and brine and latent heat enthalpy from phase change of brine:

$$
d H=f_{i} c_{i} d T+f_{b} c_{b} d T+L d f_{b}
$$

Where $f_{i}$ is the massic fraction of ice in the mixture, $f_{b}=1-f_{i}$ the massic fraction of brine, $L$ the latent heat, $c_{i}$ the massic capacity of ice and $c_{b}$ the massic capacity of brine.

Values for $c_{i}, c_{b}$ and $L$ are given by [14] as a function of temperature for $c_{i}$ and $L$ or concentration for $c_{b}$.

From the definition of brine fraction, we have:

$$
d f_{b}=-\frac{f_{b}^{2}}{C_{i, 0}} d C
$$

And $d C$ can be computed from (3) as $d C=\frac{d T_{l}}{d T} d T$

We suppose here that thermal capacity is constant over temperature range of $1^{\circ} \mathrm{C}$. The thermal capacity over the temperature range is obtained by integrating $d H$ over the temperature range:

$$
c\left(T_{1} \leq T<T_{2}\right)=\frac{1}{T_{2}-T_{1}} \int_{T_{1}}^{T_{2}} d H
$$

As for data from SP5 supplier, we work with temperature ranges of $1^{\circ} \mathrm{C}$ for the brine solution. Outside of the phase change temperature range, that is to say to temperatures higher than $-4.7^{\circ} \mathrm{C}$.

We have the partial enthalpy distributions shown in figure 3. The enthalpy distribution for SP5 has an hysteresis: values for enthalpy distribution are different along the direction of temperature variation. 

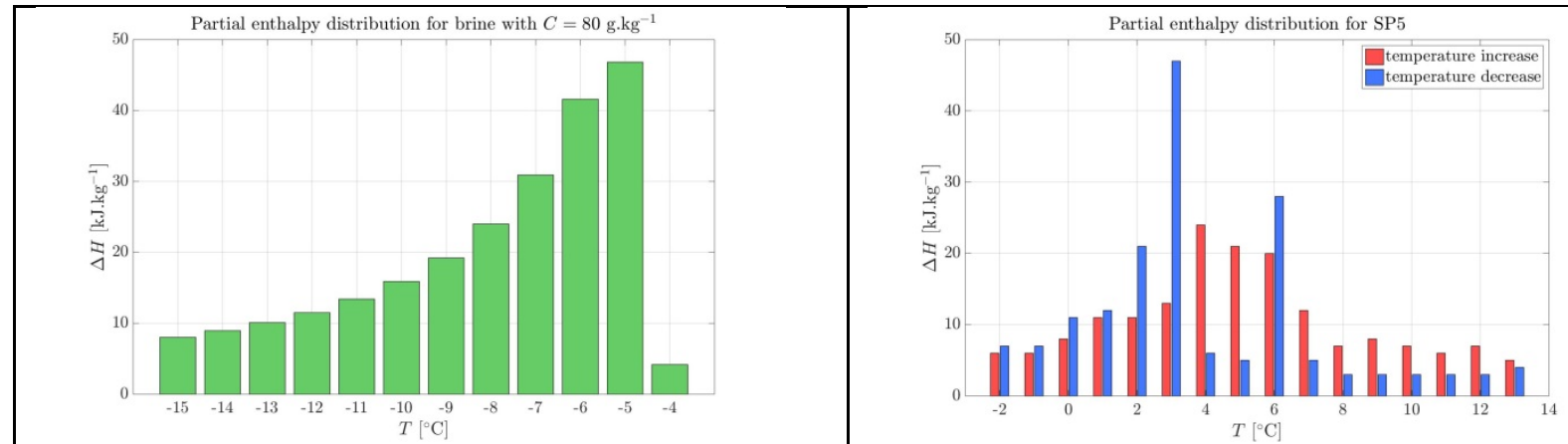

Fig. 3. Partial enthalpy distributions for brine (left) and SP5 (right)

Density of RT5HC is supposed to evaluate linearly, with $\rho=880 \mathrm{~kg} \cdot \mathrm{m}^{-3}$ for $T=-15^{\circ} \mathrm{C}$ and $\rho=760 \mathrm{~kg} \cdot \mathrm{m}^{-3}$ for $T=+20^{\circ} \mathrm{C}$. For brine solution and ice, we use data from [Levy 1982]:

$$
\begin{gathered}
\rho_{\text {brine }}=(1+0.689 C(1-0.0056 T)) \times 10^{3} \\
\rho_{\text {ice }}=0.917(1+0.000173 T) \times 10^{3}
\end{gathered}
$$

For thermal conductivity, it is supposed to be constant for SP5, equal to $0.2 \mathrm{~W} \cdot \mathrm{m}^{-1} \cdot \mathrm{K}^{-1}$, and function of both temperature and $\mathrm{NaCl}$ concentration for brine and ice. From [15]:

$$
\begin{gathered}
k_{\text {ice }}=2.25-0.006875 T(1-0.0159 T) \\
k_{\text {brine }}=(1-0.14 C)(0.562+0.001967 T(1-0.00338 T))
\end{gathered}
$$

Air temperature is shown in figure 4. In a first approach, we consider that the environmental temperature is at air temperature for radiative exchanges.

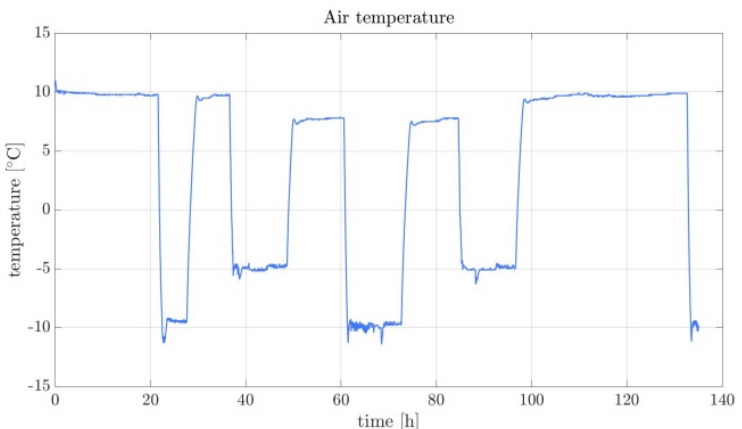

Fig. 4. Air temperature as a function of time

Results obtained by numerical simulation were conducted the air temperature evolution measured during experiments and presented in figure 4. Results obtained are presented and discussed in the following paragraph.

\section{Results and discussion}

\subsection{Identification of the PCM phase transition}

Raman and thermographic data acquisition conducted each to the generation of over 2000 respectively spectra and thermal images, covering the whole duration of the test. The phase change in the PCM could either be detected through a change in the Raman spectra signature, and through a temperature change detected at the surface of the pavement sample containing the inclusions.

When considering the surface temperature evolution monitored by the infrared camera (figure $5 \mathrm{a}$ ), it appeared a clear delay of over 10 hours before the surface temperature reached more or less the air temperature. This clearly indicated the thermal inertia of the material. The temperature variation with time also indicated two moments with some heterogeneities in its evolution, indicated in figure $5 \mathrm{a}$, These heterogeneities do correspond, with a timeshift, to thermal anomalies detected on the surface (figure $5 \mathrm{~b}$ ), which could be attributed to the phase change, with respectively a reduction in temperature decrease and increase. This is consistent with the fact that in one case some heat is released during the liquid to solid phase transition, while some energy is absorbed to the solid to liquid phase transition. 


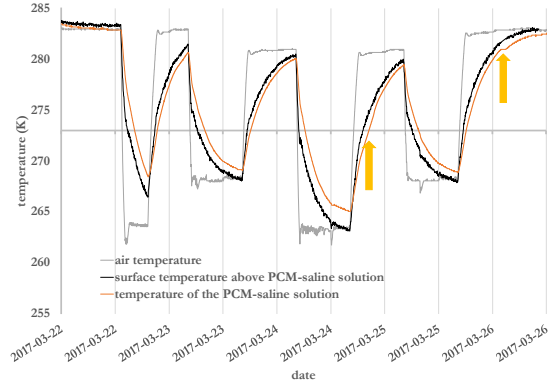

(a)
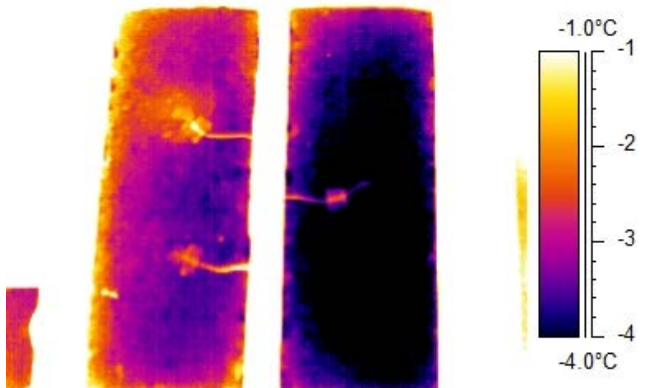

(b)

Fig. 5. Pavement surface temperature evolution above and on the saline solution-PCM inclusion (a) and thermal image of the pavements samples shortly before an air temperature increase $(b)$

Such a phase change could also indeed be detected through a PCA on both spectral and Raman data. PCA results of this data is presented in figure 6 . For both thermographic and spectroscopic data, results indicated a structure depending on the air temperature decreases, plateaus or increases.

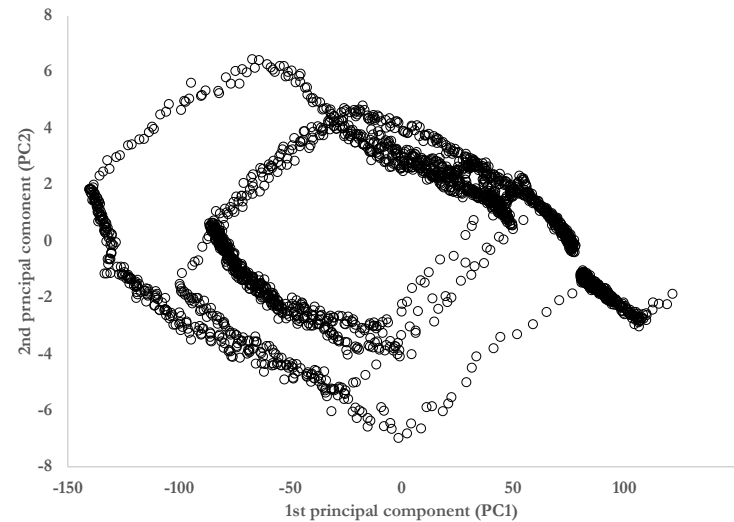

(a)

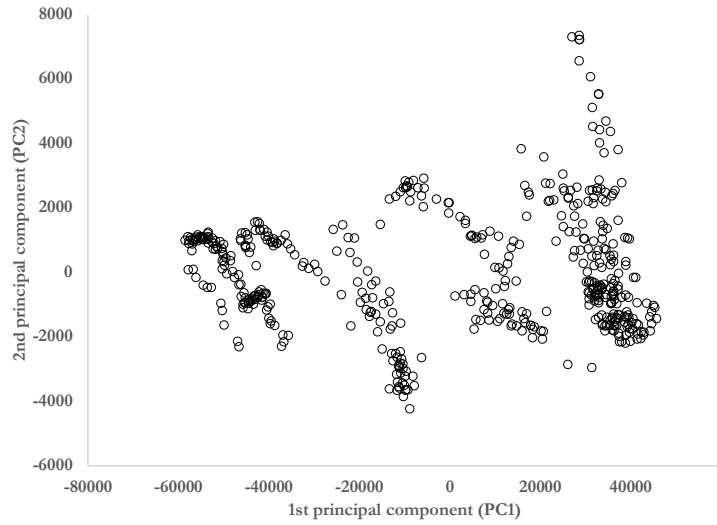

(b)

Fig. 6. PCA results on thermal images (a) and Raman spectra (b) for the whole test duration for the saline solution inclusion

The main interest was to quantify the time shift between the phase transition as detected by the Raman spectrometer and its thermal manifestation at the pavement surface. This was performed with a PCA conducted on data regarding a temperature decrease followed by a plateau including the phase transition temperature. Results are illustrated in figure 7. As indicated, the time shift between the phase transition detected spectroscopically and its thermal occurrence on pavement surface was of nearly 9 hours. This time shift was also identified for the fourth temperature decrease and seventh plateau. This time shift is quite large, and this can easily be explained by the low thermal conductivity of the material the pavement samples were made of. This low thermal conductivity is also caused by the porosity of the pavement sample.

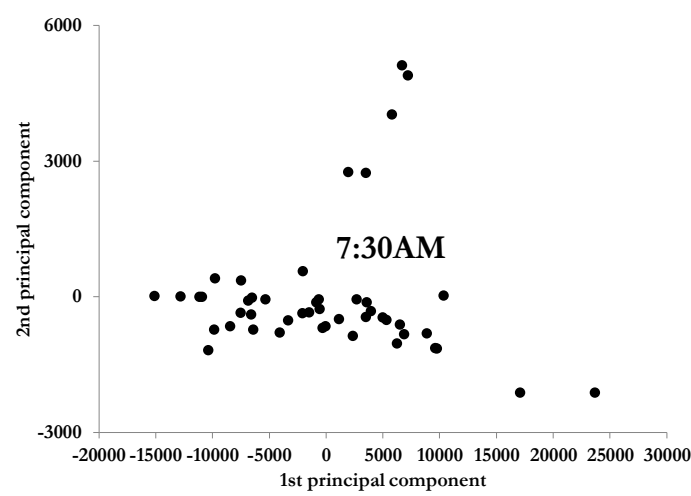

(a)

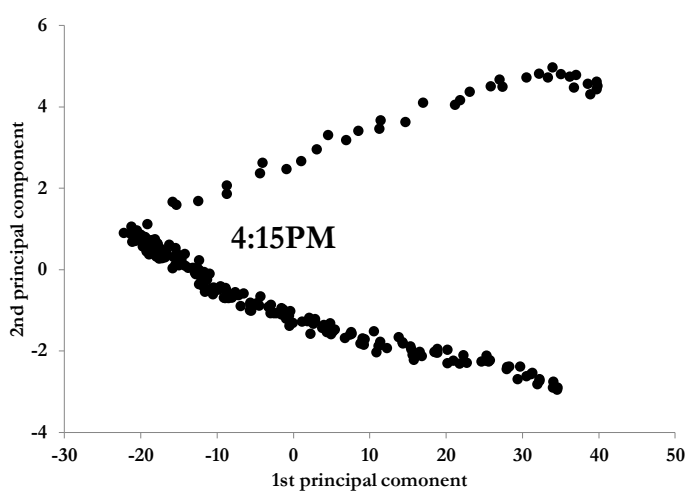

(b)

Fig. 7. PCA results on Raman spectra (a) and thermal images (b) for second temperature decrease and the third plateau 


\subsection{Comparison between measurements and thermal numerical simulations}

Temperature field computed from the model is compared with measurements realized with infrared thermography and with thermocouples inserted at surface level and inside samples. Numerical and experimental probes locations are reported in figure 8.

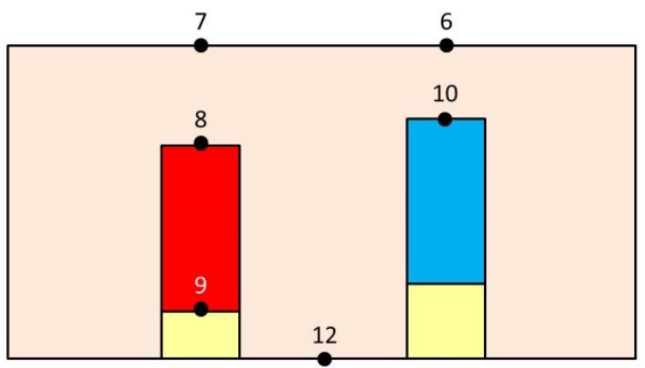

Pavement with inclusions

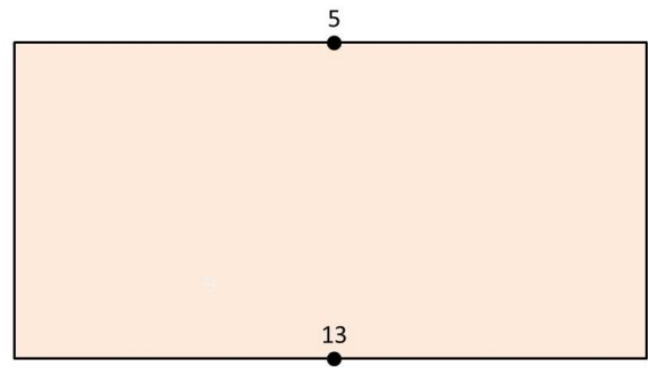

Healthy pavement

Fig. 8. Sectional view of pavement samples and probes locations with and without inclusion in figure 9.

Temperature at the surface of inclusions and for healthy pavement from measures and computation are shown

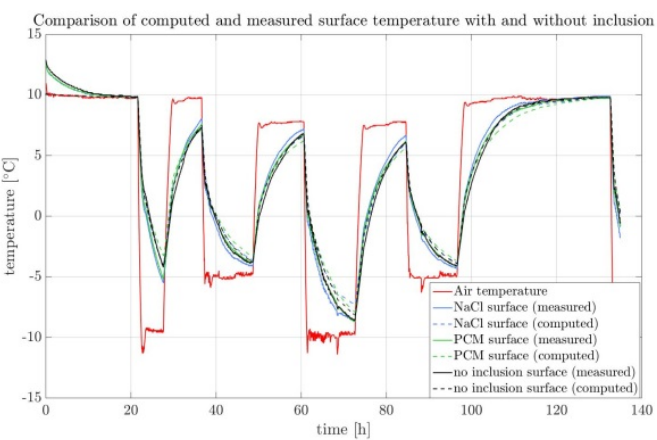

Fig. 9. Thermocouple measurements and computed surface temperature above inclusions

The effects of the inclusions on the temperature field are visible when the internal temperature is closed to values of state change. Temperature field computed from our model is shown on a vertical sectional view for $t=25$ hours in figure 10 on the left. The difference with the pavement without inclusion is also illustrated in this figure on the right.
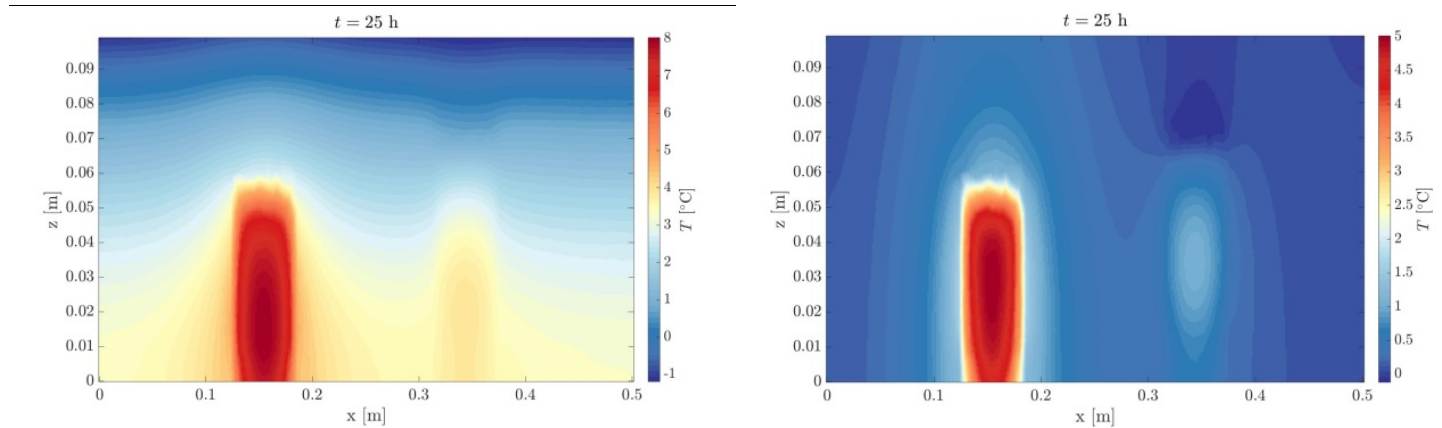

Fig. 10. Effects of inclusions on temperature field on sectional views for $y=9 \mathrm{~cm}$ at $t=25 \mathrm{~h}$. (left: temperature field, right: difference with a healthy pavement)

Even if the influence of phase change is particularly visible close to the inclusions, the temperature at the surface is also impacted by it. As for figure 8, the computed temperature at the surface of the pavement is shown in figure 11 . 

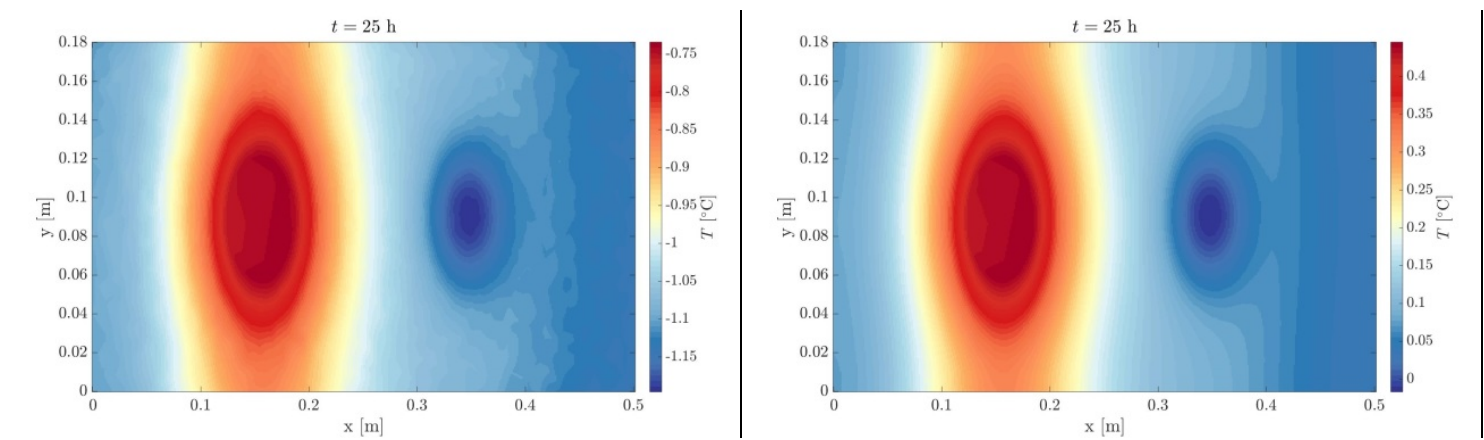

Fig. 11. Effects of inclusions on temperature field at the surface at $t=25 \mathrm{~h}$. (left: temperature field, right: difference with a healthy pavement)

This same difference on a line at the surface for $y=9 \mathrm{~cm}$ along the studied time range is plotted in figure 12 . The influence of phase change is visible when the difference of temperature reaches extrema. It can also be seen in this figure that only one phase change occurs for brine inclusion, when the air temperature is stabilized at about $-10^{\circ} \mathrm{C}$ between $t=$ $61 \mathrm{~h}$ and $73 \mathrm{~h}$.

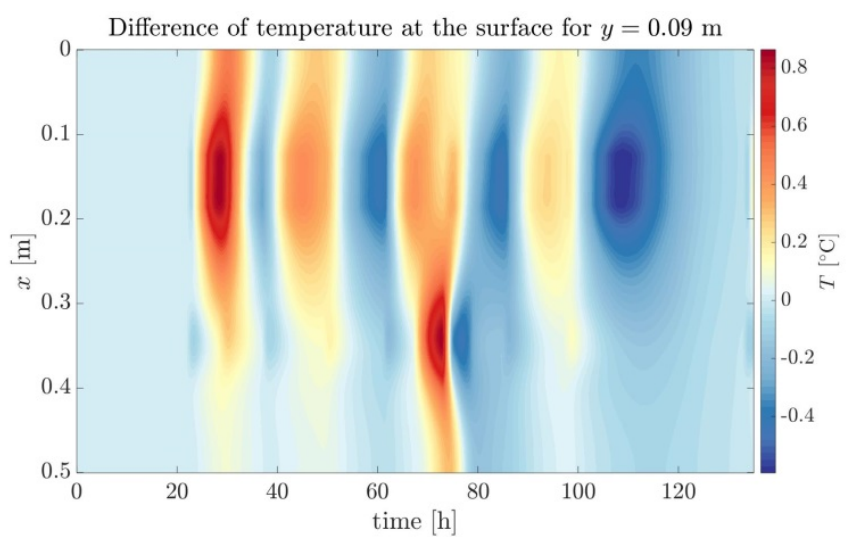

Fig. 12. Difference of temperature between pavement with two inclusions and healthy pavement at the surface for $y=9 \mathrm{~cm}$ as a function of $x$ position and time. MCP inclusion is located for $x$ between 0.123 and $0.186 \mathrm{~m}$ and brine inclusion between 0.311 and $0.375 \mathrm{~m}$

Computed temperatures are compared with measured at thermocouples. Differences above PCM and brine inclusions are shown in figure 13. Difference above healthy pavement is shown in figure 14. The absolute difference remains for the three cases below $1.5^{\circ} \mathrm{C}$ during most of the experience time.
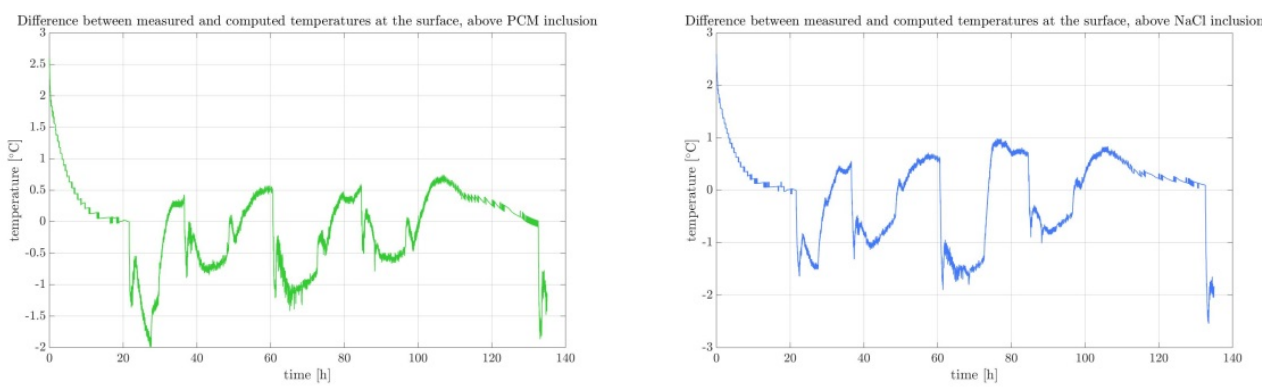

Fig. 13. Difference between measured and computed temperatures above PCM inclusion (left) and brine inclusion (right) 


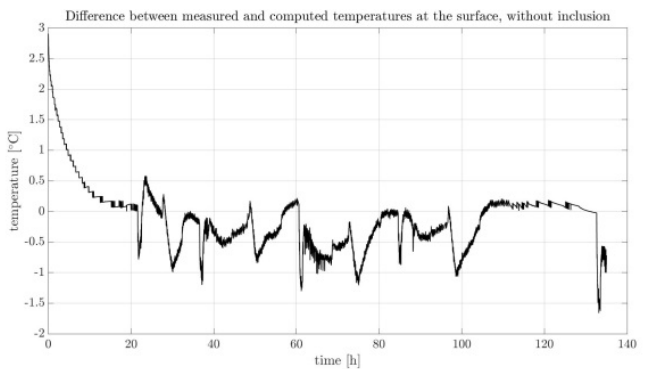

Fig. 14. Difference between measured and computed temperatures above healthy pavement

Finally, a first comparative analysis between reconstructed thermal image sequence issued from numerical simulations and experimental ones is proposed.

Simulated thermal image sequence are obtained by interpolating the surface temperature field evolution, issued from 3D numerical simulations, and using a $1 \mathrm{~mm}$ spatial step interpolation. Two sequences were generated from numerical calculations, one for the specimen with the two PCM inclusions and one for the specimen with no PCM inclusion. Using the same decomposition, the experimental thermal image sequence, has been spatially stich in two thermal sequences, one for with the two PCM inclusions and one for the specimen with no PCM inclusion.

A principal component analysis by using Singular Value Decomposition [16] was applied to the first air temperature decay. Results obtained for second empirical orthogonal function (EOF) maps are presented in figure 15.

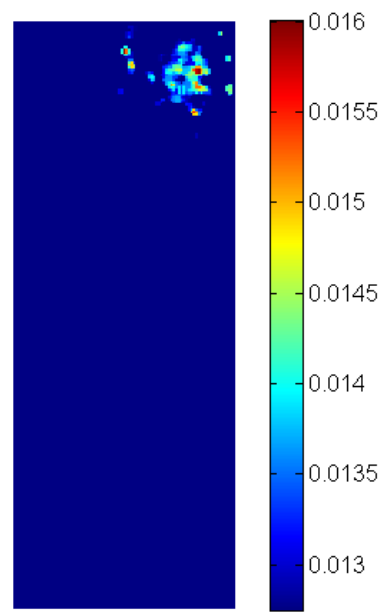

(a)

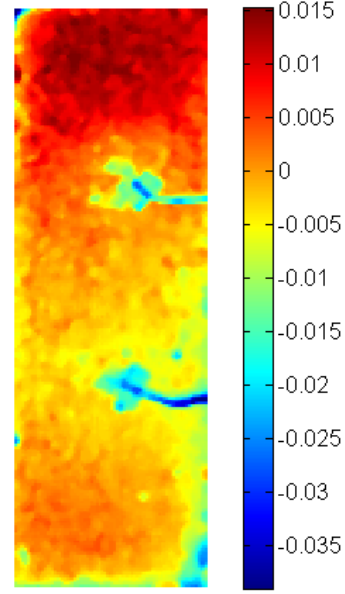

(b)

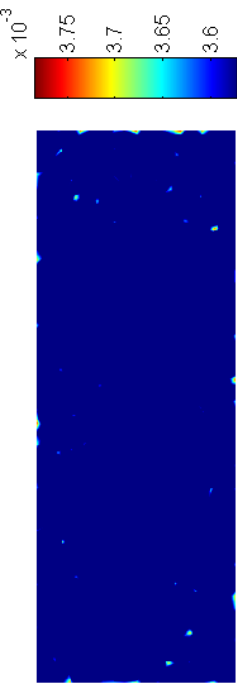

(c)

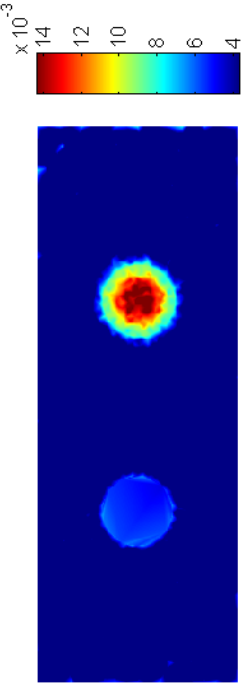

(d)

Fig. 15. Second empirical orthogonal function maps (EOF2) calculated for the first air temperature decay: Experimental results (left (a) no inclusion, left (b) 2 inclusions)

Numerical simulations results (right (c) no inclusion, right (d) 2 inclusions)

For the specimen with no inclusion (a) and (c) same trends are observed in the second EOF maps. Anyway, some undesirable convective effects are present in the experimental map (upper right).

For the specimen with two inclusions, (b) and (d) difference of behaviour depending of the nature of PCM materials can be observed. Difference of behaviour is clearly visible in second EOF map calculated using numerical simulations and more difficult to observe on experimental one. Two perturbations are affecting the experimental results, one is due to convective effect in the climatic chamber used for experiments (see upper part of map) and the second one is induced by thermocouples glued at specimen surface. Furthermore, numerical simulations consider that the specimen is homogeneous, but experiments are affected by noise induced by the mix of aggregates and binder.

\section{Conclusion}

The objective of this research was to investigate to what extent the solid to liquid phase transition of Phase Change Material (PCM) inclusions into pavement were able to generate enough heat to be considered for the avoidance of ice occurrence and reducing snow accumulation. One asphalt concrete received two PCM inclusions and was submitted to controlled air temperature cycles representative of winter. The surface temperature variations were compared to another pristine asphalt concrete sample. The main concern was to identify the moment where the phase transition took place to 
clearly identify the timeshift between the energy release and its availability at the pavement surface. To do so, a spectroscopic Raman monitoring was specifically dedicated to the PCM, while an infrared camera recorded the variations of the surface temperatures of both pavement samples.

The analysis of both Raman spectra and infrared images by means of a multivariate data analysis tool clearly allowed to detecting both the phase transition and its surfacic thermal effect. The timeshift reached nine hours in the selected experimental conditions.

A new set of experiments will be planed in a near future to confirm trends observed by using SVD analysis. In particular, duration of constant cold and hot periods will be extended to favour a complete phase change in PCM material, along with an enhancement of the thermal signature effect.

\section{Acknowledgments}

The authors will like to thank the French Ministry of "Transition Écologique et Solidaire" for supporting part of this work under grant agreement DGITM N 17/389.

\section{REFERENCES}

[1] Petty K. R., Mahoney, WP. The U.S. Federal Highway Administration winter road Maintenance Decision Support System (MDSS): Recent enhancements and refinements. Proceedings of the 14th SIRWEC, Prague, Czech Republic, 14-16 May, 2008.

[2] Suaire R., Durickovic I., Derombise G. Marchetti M. Transfer, Exchanges and Effects of Road Deicing Salts in a Detention Pond Treating Road Water. Energy Procedia, 36, pp. 1296-1299, December 2013.

[3] Khalifa A., Marchetti M., Buès M., Appreciation of the traffic effects on the RST by infrared thermography. SPIE Optics+Photonics International Conference, San Diego (California, USA), 17-21 august 2014.

[4] Marchetti M., Khalifa A., Bues M., Methodology to forecast road surface temperature with Principal Components Analysis and Partial Least-Square regression. Application to a urban configuration. Advances in Meteorology, 2015.

[5] Khalifa A., Marchetti M., Bouilloud L., Martin E., Bues M., Chancibaut K. Accounting for anthropic energy flux of traffc in winter urban road surface temperature simulations with TEB model. Geosci. Model Dev., 9, 547-565, 2016.

[6] Khalifa A., Bouzouidja R., Marchetti M., Buès M., Bouilloud L., Martin E., Chancibaut K. Individual contributions of anthropogenic physical processes associated to urban traffic in improving the road surface temperature forecast using TEB model. In press (http://www.sciencedirect.com/science/article/pii/S2212095517300792, accessed December 1st 2017).

[7] Eugster W.J. Road and Bridge Heating Using Geothermal Energy. Overview and Examples, Proceedings of the European Geothermal Congress, 30th May-1st June 2007, Unterhaching (Germany).

[8] Marchetti M., Dumoulin J., Le Touz N., Moutton M., Ludwig L., Gabet T., Piau J-M., Ibos L., Infrared thermography applied to surface temperature survey of enhanced pavement sample addressing self-de-icing functionality. QIRT-Asia Conference on quantitative infrared thermography, Mamallapuram (Inde), 6-10 juillet 2015.

[9] Marchetti M., Fois M., Ibos L., Dumoulin J., Bourson P., Piau J.-M. Comparative study in the identification of liquid to solid transition phase with DSC, Raman spectra analysis and chemiometrics methods applied to phase change materials used for icing-delay in civil engineering infrastructures. Applied Thermal Engineering. Applied Thermal Engineering, Volume 130, 5 February 2018, pp. 49-61.

[10] Zienkiewicz, O. C., Taylor, R. L. and Zhu, J. Z., The finite element method: its basis and fundamentals, sixth edition, Elsevier Butterworth-Heinemann, Oxford, 2005

[11] Asfour, S., Bernardin, F., Toussaint, E. and Piau, J.-M., Hydrothermal modeling of porous pavement for its defreezing, Applied Thermal Engineering, Vol. 107, pp. 493-500, 2016

[12] Incropera, F. P., DeWitt, D. P., Bergman, T. L. et Lavine, A. S., Fundamentals of Heat and Mass Transfer, sixth edition, John Wiley \& Sons, New York, 2006

[13] Rubitherm : https://www.rubitherm.eu/en/index.php/products/sp-5

[14] Aguirre-Puente, J., Posado, R., Ramos, M. and Sanz, P. D., Contribution à l'étude du changement de phase de solutions aqueuses,Proceedings of the fifth Canadian Permafrost Conference, Vol. 54, pp. 61-68, 1990

[15] Levy, F. L., The thermal conductivity of commercial brines and seawater in the freezing range, International Journal of Refrigeration, Vol. 5, N. 3, pp. 155-159, 1982.

[16] Rajic N., "Principal component thermography for flaw contrast enhancement and flaw depth characterization in composite structures", Composite Structures, vol 58, pp 521-528, 2002. 